\title{
Penentuan Nilai Ekivalen Kendaraan Ringan (Ekr) Untuk Kendaraan Becak Motor (Bentor) Pada Ruas Jalan Arif Rahman Hakim dan Jalan Manggis Kota Gorontalo
}

\author{
Fitriyanti Ui ${ }^{1}$, Yuliyanti Kadir ${ }^{2}$, Marike Mahmud ${ }^{3}$ \\ ${ }^{1}$ Program Studi Teknik Sipil, Fakultas Teknik Sipil Universitas Negeri Gorontalo \\ ${ }^{2}$ Program Studi Teknik Sipil, Fakultas Teknik Sipil Universitas Negeri Gorontalo \\ ${ }^{3}$ Program Studi Teknik Sipil, Fakultas Teknik Sipil Universitas Negeri Gorontalo
}

\begin{abstract}
The equivalent value of light vehicles (elv) is influenced by the size and speed of the vehicle, the greater the vehicle the equivalent value of light vehicles (elv) the higher, the higher the vehicle speed the equivalent value of light vehicles (elv) will be lower. The purpose of this study is to determine the equivalent value of light vehicles (elv) for motor tricycles vehicle (mtv) as part of the traffic and the performance of the Arif Rahman Hakim Road and Gorontalo City Manggis Road. The location of the study was conducted on Jalan Arif Rahman Hakim and Manggis Street. Primary data collected is data of traffic flow volume. The analysis was carried out using the simple linear regression analysis method and the 2014 Indonesian road capacity guidelines. From the calculation results obtained an equivalent value of light vehicles (elv) for motor tricycles vehicle (mtv) on the Arif Rahman Hakim Road section of 0.55 and on the Manggis Road section obtained an equivalent value of light vehicles (elv) of 0.46 . Then do the calculations to analyze the performance of the Arif Rahman Hakim and Manggis Roads obtained the degree of saturation (DS) $<0.85$. The DS scores show that both locations are very suitable to serve the flow of traffic during peak hours.
\end{abstract}

Keywords-elv, motor tricycles vehicle, linear regression, road performance

Abstrak-Nilai ekivalen kendaraan ringan (ekr) dipengaruhi oleh besar dan kecepatan kendaraan, makin besar kendaraan maka nilai ekivalen kendaraan ringan (ekr) makin tinggi, makin tinggi kecepatan kendaraan maka nilai ekivalen kendaraan ringan (ekr) makin rendah. Tujuan penelitian ini yaitu untuk mengetahui nilai ekivalen kendaraan ringan (ekr) untuk kendaraan becak motor (bentor) sebagai bagian dari lalu lintas dan kinerja ruas Jalan Arif Rahman Hakim dan Jalan Manggis Kota Gorontalo. Lokasi penelitian dilakukan pada ruas Jalan Arif Rahman Hakim dan ruas Jalan Manggis. Data primer yang dikumpulkan adalah data volume arus lalu lintas. Analisis dilakukan dengan menggunakan metode analisis regresi linier sederhana dan pedoman kapasitas jalan Indonesia 2014. Dari hasil perhitungan diperoleh nilai ekivalen kendaraan ringan (ekr) untuk kendaraan bentor (bentor) pada ruas Jalan Arif Rahman Hakim sebesar 0,55 dan pada ruas Jalan Manggis diperoleh nilai ekivalen kendaraan ringan (ekr) sebesar 0,46. Kemudian dilakukan perhitungan menganalisis kinerja ruas jalan Arif Rahman Hakim dan Jalan Manggis diperoleh nilai derajat kejenuhan (DJ) $<\mathbf{0 , 8 5}$. Hasil nilai DJ menunjukkan bahwa kedua lokasi sangat layak untuk melayani arus lalu lintas di jam sibuk.

Kata Kunci-Ekr, Regresi Linier, Kinerja Jalan

\section{Pendahuluan}

\section{Latar Belakang}

Perencanaan geometrik jalan raya, kapasitas jalan dihitung berdasarkan volume lalu lintas yang terlebih dahulu dikonversikan dalam satuan kendaraan ringan (ekr). Faktor konversi dari berbagai macam kendaraan tersebut menjadi kendaraan ringan dikenal dengan ekr (ekivalen kendaraan ringan). Satuan kendaraan ringan (skr) adalah satuan kendaraan di dalam arus lalu lintas yang disetarakan dengan kendaraan ringan / mobil penumpang, besaran skr dipengaruhi oleh tipe / jenis kendaraan, dimensi kendaraaan, dan kemampuan olah gerak. Sedangkan ekivalensi kendaraan dengan mobil penumpang tergantung besar dan kecepatan kendaraan.

Masing-masing ruas jalan memiliki karakteristik lalu lintas dan kondisi geometrik jalan yang berbeda. Kondisi geometrik meliputi lebar jalan, jumlah jalur serta panjang landai. Hal tersebut mempengaruhi nilai ekr. Nilai ekr juga berbeda untuk setiap bagian jalannya. Besar nilai ekr untuk simpang berbeda dengan nilai ekr untuk ruas jalan. Nilai ekr mempengaruhi kinerja dari 
sebuah ruas jalan atau sebuah simpang. Oleh karena itu agar kebijakan yang di ambil dalam rangka mengatasi suatu konflik sesuai dengan kondisi di lapangan, maka dibutuhkan suatu nilai ekr yang sesuai dengan keadaan jalan sebenarnya.

Nilai ekr untuk Indonesia telah diatur dalam Pedoman Kapasitas Jalan Indonesia 2014 (PKJI'14). Pedoman Kapasitas Jalan Indonesia 2014 (PKJI'14) adalah pemutakhiran dari Manual Kapasitas Jalan Indonesia 1997 (MKJI'97). Adanya perubahan populasi kendaraan, komposisi kendaraan, sehingga perlu dikaji dampaknya terhadap kapasitas jalan. Pemutakhiran ini, pada umumnya terfokus pada nilai-nilai ekivalen satuan kendaraan ringan (skr) atau ekivalen kendaraan ringan (ekr).

Salah satu obyek permasalahan yang tidak kalah pentingnya adalah kendaraan becak motor (bentor) merupakan kendaraan yang dipergunakan untuk mengangkut orang atau masyarakat umum dari suatu tempat ke tempat lain yang banyak beroperasi di kota Gorontalo. Keberadaan kendaraan (bentor) juga mengalami pertumbuhan yang sangat pesat. Kendaraan bentor akan membutuhkan ruang gerak yang cukup dalam bermanuver di ruas jalan maupun persimpangan. Seperti mobil dalam pengoperasiannya tidak sama dengan truk dan sepeda motor. Perbedaan ini meliputi kemampuan memulai gerakan dan mengadakan jarak antar kendaraan. Dengan kata lain kendaraan becak motor (bentor) dapat mempengaruhi kecepatan kendaraan lain dalam berlalu lintas. Berdasar pada kondisi tersebut perlu kajian nilai ekivalen kendaraan ringan (ekr) untuk kendaraan bentor yang sesuai, berkaitan perannya sebagai bagian dari lalu lintas.

Untuk itu perlu di teliti sejauh mana pengaruh kendaraan becak motor (bentor) pada kinerja lalu lintas dan perlu kajian nilai ekivalen kendaraan ringan (ekr) untuk kendaraan becak motor (bentor) yang sesuai, berkaitan perannya sebagai bagian dari lalu lintas pada ruas jalan. Penelitian ini dilakukan pada ruas Jalan Arif Rahman Hakim (lokasi 1) dan ruas Jalan Manggis (lokasi 2) di Kota Gorontalo yang merupakan tipe jalan tak terbagi (2/2 TT). Pemilihan lokasi tersebut didasarkan atas besarnya potensi volume kendaraan becak motor (bentor).

Sejauh ini telah banyak dilakukan penelitian untuk mendapatkan nilai ekr Metode yang dapat digunakan untuk mendapatkan nilai ekr yaitu metode semi empiris, metode Walker's, metode headway, regresi linier, koefisien homogenic, dan metode simulasi. Metode yang akan digunakan dalam penelitian kali ini adalah metode analisis regresi linier sederhana. Metode tersebut telah umum digunakan dalam penelitianpenelitian sebelumnya. Digunakan analisis regresi linier karena setiap jenis kendaraan mempunyai pengaruh masing-masing terhadap jenis kendaraan lainnya.
Penelitian yang akan di bahas dapat diidentifikasi permasalahannya sebagai berikut:

1. Nilai ekivalen kendaraan ringan (ekr) untuk Indonesia telah diatur dalam Pedoman Kapasitas Jalan Indonesia 2014 (PKJI'14). Nilai ekivalen kendaraan ringan (ekr) tersebut bukan angka mutlak tetapi dapat berubah dari waktu ke waktu.

2. Jumlah kendaraan becak rmotor (bentor) yang terus meningkat pada ruas Jalan Kota Gorontalo mengakibatkan perubahan karakteristik arus lalu lintas. Perubahan karakteristik tersebut berpengaruh pada nilai ekivalen kendaraan ringan (ekr). Nilai ekivalen kendaraan ringan (ekr) sangat penting fungsinya dalam hal analisis kinerja jalan, menentukan kelas jalan pada perencanaan geometrik jalan dan studi kelayakan jalan.

3. Dalam menata sistem operasi kendaraan becak motor (bentor) di Kota Gorontalo adalah aspek legalnya, karena jika di tinjau dari jenis sistem penomoran kendaraan becak motor (bentor) bukanlah kendaraan umum seperti yang di sebutkan dalam Undangundang Republik Indonesia Nomor 22 Tahun 2009 tentang lalu lintas dan angkutan jalan.

4. Penelitian ini dilakukan karena belum ada nilai ekivalen kendaraan ringan (ekr) kendaraan becak motor (bentor) pada Pedoman Kapasitas Jalan Indonesia 2014 (PKJI'14) secara spesifik.

\section{A. Rumusan Masalah}

Berdasarkan latar belakang masalah yang telah diuraikan diatas, maka dapat diambil rumusan masalah yaitu :

1. Berapa nilai ekivalen kendaraan ringan (ekr) untuk kendaraan becak motor (bentor) sebagai bagian dari lalu lintas pada ruas Jalan Arif Rahman Hakim dan Jalan Manggis berdasarkan perhitungan metode analisis regresi linier sederhana?

2. Bagaimana kinerja ruas Jalan Arif Rahman Hakim dan Jalan Manggis Kota Gorontalo?

\section{B. Tujuan Penelitian}

Berdasarkan rumusan masalah diatas, maka tujuan penelitian ini yaitu:

1. Menganalisis nilai ekivalen kendaraan ringan (ekr) untuk kendaraan becak motor (bentor) sebagai bagian dari lalu lintas di ruas Jalan Arif Rahman Hakim dan Jalan Manggis dengan metode analisis regresi linier sederhana.

2. Mengetahui kinerja ruas Jalan Arif Rahman Hakim dan Jalan Manggis Kota Gorontalo.

\section{Batasan Masalah}

Pembatasan masalah dalam penelitian ini perlu diberikan agar penelitian dapat dilakukan secara efisien, efektif dan tidak menyimpang dari tujuan penelitian. Adapun batasan masalah pada penelitian ini adalah sebagai berikut:

\section{Identifikasi Masalah}




\section{1) Batasan Wilayah Kajian}

Batasan wilayah kajian pada penelitian ini adalah:

1 Lokasi penelitian dilakukan pada ruas Jalan Arif Rahman Hakim dan ruas Jalan Manggis.

2 Segmen yang menjadi objek penelitian pada ruas Jalan Arif Rahman Hakim (lokasi 1) yaitu dari simpang tiga Jalan Kalimantan sampai dengan simpang tiga Jalan Dewi Sartika. Dan Segmen yang menjadi objek penelitian pada ruas Jalan Manggis (lokasi 2) yaitu dari simpang tiga Jalan Nangka sampai dengan simpang tiga Jalan Manggis 1.

\section{2) Batasan Materi Kajian}

Batasan materi yang akan di bahas pada penelitian ini meliputi:

1 Nilai ekivalen kendaraan ringan (ekr) yang dicari adalah nilai ekivalen kendaraan ringan (ekr) untuk kendaraan becak motor (bentor).

2 Kendaraan yang diamati adalah sepeda motor (SM), kendaraan becak motor (BENTOR), kendaraan ringan $(\mathrm{KR})$, kendaraan berat $(\mathrm{KB})$ dan kendaraan tak bermotor (KTB).

3 Metode perhitungan yang digunakan untuk mendapatkan nilai ekivalen kendaraaan ringan (ekr) adalah metode analisis regresi linier sederhana.

4 Penelitian ini menggunakan Pedoman Kapasitas Jalan Indonesia 2014 (PKJI'14).

\section{Manfaat Penelitian} adalah:

Manfaat yang diharapkan dari hasil penelitian

\section{1) Manfaat Akademis}

1 Memperluas pengetahuan dan wawasan tentang cara menghitung nilai ekivalens kendaraan ringan (ekr) berdasarkan metode analisis regresi linier sederhana dari data-data yang di peroleh di lapangan.

2 Dapat menjadi salah satu referensi untuk penelitianpenelitian mengenai nilai ekivalen kendaraan ringan (ekr) selanjutnya.

3 Menerapkan dan meningkatkan pemahaman ilmu yang di peroleh di perkuliahan dan memberikan sumbagan bagi pengembangan di bidang transportasi.

4 Sebagai masukan bagi instansi terkait dalam upaya peningkatan kinerja ruas jalan yang lebih baik.

\section{2) Manfaat Praktis}

Menjadi salah satu alternatif jika nilai ekivalen kendaraan ringan (ekr) berdasarkan metode Pedoman Kapasitas Jalan Indonesia 2014 (PKJI'14) tidak sesuai dengan kondisi yang ada di lapangan.

\section{Landasan Teori}

\section{1) Analisis Regresi Linear Sederhana}

Regresi linear sederhana (simple analisis regresi) hanya digunakan untuk satu variabel bebas (independent) dan satu variabel tak bebas (dependent). Rumus analisis regresi linier sederhana yaitu :

$$
Y=\mathrm{a}+\mathrm{b} x
$$

Dimana :

$$
\begin{array}{ll}
\text { Y } & \text { : Variabel tak bebas } \\
\mathrm{X} & \text { : Variabel bebas } \\
\mathrm{a} & \text { : Konstanta regresi } \\
\mathrm{b} & \text { : Koefisien regresi }
\end{array}
$$

Besarnya konstanta regresi (a) dan konstanta arah regresi (b) dapat ditentukan menggunakan persamaan :

$$
\begin{aligned}
& \mathrm{b}=\frac{n \sum x y-\sum x \cdot \sum y}{n \sum x^{2}-\left(\sum x\right)^{2}} \\
& \mathrm{a}=\frac{\sum y-b x}{n}
\end{aligned}
$$

Dimana :

$n \quad$ : Banyaknya Sampel

$a$ dan $b$ adalah koefisien yang dicari dari data arus lalu lintas dan komposisi kendaraan yang ada. Dengan rumus persamaan diatas akan dihitung koefisien-koefisien regresi (angka ekivalen kendaraan ringan) dari persamaan analisis regresi linier sederhana.

\section{2) Koefisien Korelasi ( $r$ )}

Koefisien korelasi digunakan untuk menentukan korelasi antara peubah bebas dan peubah tidak bebas. Dapat di ketahui tingkat hubungan variabel bebas dan variabel tak bebas dengan cara :

$$
r=\frac{n \sum x y-\left(\sum x\right)(\Sigma y)}{\sqrt{\left[n \sum x^{2}-\left(\sum x\right)^{2}\right]\left[n \sum y^{2}-\left(\sum y\right)^{2}\right]}}
$$

\section{Dimana :}

$$
\begin{array}{ll}
r & : \text { Koefisien Korelasi } \\
n & : \text { Banyaknya Sampel } \\
\mathrm{x} & : \text { Variabel Bebas } \\
\mathrm{y} & : \text { Variabel Terikat }
\end{array}
$$

Untuk mengetahui keeratan hubungan antara dua variabel dengan menggunakan koefisien korelasi adalah dengan menggunakan nilai absolut dari koefisien tersebut. Besarnya koefisien korelasi (r) antara dua variabel adalah nol sampai dengan 1. Apabila dua buah variabel mempunyai nilai $r=0$, berarti antara dua variabel tersebut tidak ada hubungan. Sedangkan apabila dua buah variabel mempunyai $r= \pm 1$, maka dua buah variabel tersebut mempunyai hubungan yang sempurna.

Semakin tinggi nilai koefisien korelasi antara dua buah variabel (semakin mendekati 1), maka tingkat keeratan hubungan antara dua variabel tersebut semakin tinggi . dan sebaliknya semakin rendah koefisien korelasi antara dua buah variabel (semakin mendekati 0), maka tingkat keeratan hubungan antara dua variabel tersebut semakin lemah.

Setelah di ketahui nilai koefisien korelasi ( $\mathrm{r}$ ) kemudian di interpretasikan kedalam tabel Interpretasi Koefisien Korelasi Nilai $\mathrm{r}$ dapat dilihat seperti pada Tabel 1. 
Tabel 1 Interprestasi Koefisien Korelasi Nilai r

\begin{tabular}{cc}
$\begin{array}{c}\text { Interval Koefisien } \\
(\mathbf{r})\end{array}$ & Tingkat Hubungan \\
\hline $0,00-0,199$ & Hubungannya Sangat \\
$0,20-0,399$ & Rendah \\
$0,4-0,599$ & Hubungannya Rendah \\
$0,6-0,799$ & Hubungannya Sedang \\
$0,8-1,000$ & Hubungannya Kuat \\
\hline Kumber $:$ Sugiyono & Kuat \\
\hline
\end{tabular}

Sumber : Sugiyono (2013:250)

\section{3) Koefisien Determinasi (KD)}

Koefisien Determinasi merupakan ukuran untuk mengetahui besarnya pengaruh keseluruhan variabel bebas terhadap variabel tak bebas. Digunakan teknik statistik dengan menghitung besarnya koefisien determinasi. Koefisien determinasi dihitung dengan mengkuadratkan koefisien korelasi yang telah ditemukan, yang selanjutnya dikalikan dengan $100 \%$ dimana koefisien determinasi dinyatakan dalam bentuk persen. Dapat di ketahui tingkat pengaruh variabel $x$ dan variabel y dengan cara :

$$
K D=r^{2} \times 100 \%
$$

Dimana :

KD $\quad$ Koefisien Determinasi

Setelah diketahui nilai koefisien determinasi (KD) kemudian di interpretasikan kedalam tabel Interpretasi Koefisien Determinasi Nilai $r^{2}$ dapat dilihat seperti pada Tabel 2.

\begin{tabular}{|c|c|}
\hline $\begin{array}{c}\text { Interval Koefisien } \\
\qquad\left(\mathbf{r}^{2}\right)\end{array}$ & Tingkat Pengaruh \\
\hline $\mathrm{r}^{2}=0 \%$ & Tidak Ada Pengaruh \\
\hline $0 \%<\mathrm{r}^{2}<4 \%$ & $\begin{array}{c}\text { Pengaruhnya Rendah } \\
\text { Sekali }\end{array}$ \\
\hline $4 \% \leq \mathrm{r}^{2}<16 \%$ & Pengaruhnya Rendah \\
\hline $16 \% \leq \mathrm{r}^{2}<36 \%$ & Pengaruhnya Sedang \\
\hline $36 \% \leq r^{2}<64 \%$ & Pengaruhnya Tinggi \\
\hline$r^{2} \geq 64 \%$ & $\begin{array}{c}\text { Pengaruhnya Tinggi } \\
\text { Sekali }\end{array}$ \\
\hline
\end{tabular}

Sumber : Sugiyono (2013:259)

\section{Kinerja Lalu Lintas Jalan dengan Metode PKJI 2014}

\section{Kecepatan Arus Bebas}

Kecepatan arus bebas didefinisikan sebagai kecepatan pada tingkat arus nol, yaitu kecepatan yang akan dipilih pengemudi jika mengendarai kendaraan bermotor tanpa dipengaruhi oleh kendaraan bermotor lain dijalan. Menurut PKJI 2014, kecepatan arus bebas dapat dihitung menggunakan persamaan 6 .

$$
V_{B}=\left(V_{B D}+V_{B L}\right) \times F V_{B H S} \times F V_{B U K}
$$

\section{Kapasitas ( $C$ )}

Menurut Pedoman Kapasitas Jalan Indonesia 2014 (PKJI'14), kapasitas adalah arus lalu lintas maksimum yang dapat dipertahankan pada kondisi tertentu (geometric, distribusi arah, dan komposisi lalu lintas, serta faktor lingkungan). Kapasitas adalah salah satu faktor untuk mendapatkan derajat kejenuhan $\left(D_{J}\right)$. Persamaan dasar menentukan kapasitas (C) dapat dihitung menggunakan persamaan 7 .

$C=C_{0} x F C_{L J} x F C_{P A} x F C_{H S} x F C_{U K}$

\section{Derajat Kejenuhan (DJ)}

Derajat kejenuhan $\left(D_{J}\right)$ didefinisikan sebagai rasio arus terhadap kapasitas yang digunakan sebagai faktor kunci dalam penentuan kinerja lalu lintas pada simpang maupun ruas jalan. Nilai $\mathrm{D}_{\mathrm{J}}$ menunjukkan apakah ruas jalan bermasalah dengan kapasitas atau tidak. $D_{J}$ dihitung dengan menggunakan arus dan kapasitas yang dinyatakan dalam skr/jam. $\mathrm{D}_{\mathrm{J}}$ dihitung menggunakan persamaan 8 .

$$
\mathrm{D}_{\mathrm{J}}=\mathrm{Q} / \mathrm{C}
$$

\section{Metode Penelitian}

\section{A. Lokasi Penelitian}

Berdasarkan hasil pengamatan visual ditetapkan lokasi penelitian yaitu ruas Jalan Arif Rahman Hakim (lokasi 1) dan ruas Jalan Manggis (lokasi 2).

Lokasi penelitian I dilakukan di ruas Jalan Arif Rahman Hakim sepanjang 500 meter. Lokasi penelitian di ruas Jalan Arif Rahman Hakim (lokasi 1) seperti pada Gambar 1.

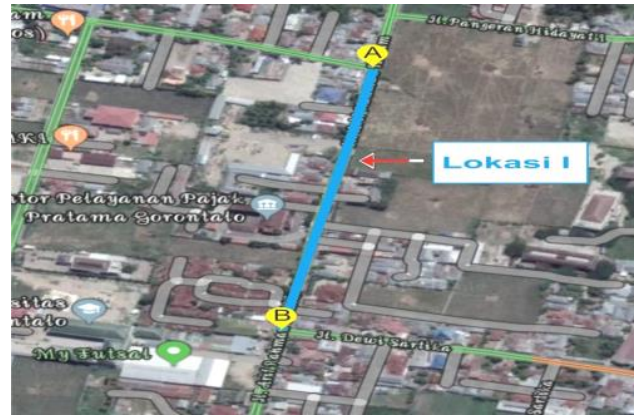

Gambar 1 Lokasi Penelitian Ruas Jalan Arif Rahman Hakim (lokasi 1)

Lokasi 2 bertempat di ruas Jalan Manggis sepanjang 750 meter. Lokasi penelitian di ruas Jalan Manggis (lokasi 2) seperti pada Gambar 2. 


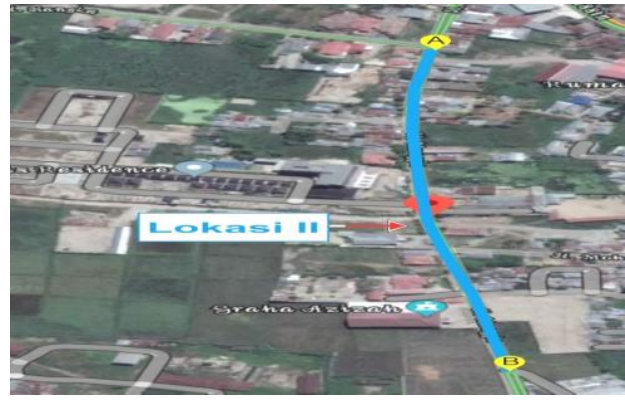

Gambar 2 Lokasi Penelitian Ruas Jalan Manggis (lokasi 2)

\section{B. Alat Penelitian}

\section{Meteran}

2 Alat tulis

3 Formulir survei volume kendaraan

4 Kamera

5 Penghitung waktu (Stopwatch)

6 Laptop computer sebagai alat untuk menghitung dan mengolah data

\section{Metode Pengumpulan Data}

Data-data yang digunakan untuk analisis didapat dengan cara pengumpulan data primer sesuai dengan kebutuhan penelitian.

\section{1) Pengumpulan Data Primer}

Data primer yang diperlukan adalah survei data volume lalu lintas harian rata-rata kendaraan (LHR) dilakukan di ruas Jalan Arif Rahman Hakim dan ruas Jalan Manggis. LHR yang dihitung yaitu gerak kendaraan sepeda motor (SM), kendaraan ringan (KR), kendaraan berat $(\mathrm{KB})$, kendaraan tak bermotor (KTB) dan kendaraan becak motor (bentor) sepanjang ruas jalan tertentu. Penghitungan LHR dilakukan menggunakan kamera video sebagai alat bantu dalam merekam data kondisi jalan. Hal ini dilakukan demi menghindari terjadinya kesalahan-kesalahan yang mungkin terjadi pada saat pengambilan data. Adapun cara pelaksanaan survei arus lalu lintas adalah :

1) Pencatatan dilakukan setiap interval waktu 15 menit.

2) Jumlah kendaraan yang diamati langsung dicatat pada formulir survei. Pencatatan dilakukan dengan turus.

\section{2) Pelaksanaan Pengumpulan Data}

Pelaksanaan pengumpulan data dan informasi dilakukan dengan pengumpulan data survei lapangan. Survei lapangan dilakukan dengan pengamatan, observasi visual, pengukuran dan perhitungan dilapangan untuk memperoleh data dan gambaran serta informasi yang sebenarnya tentang kondisi yang terjadi dilapangan.

Adapun tahapan survei pengumpulan data dilakukan dalam 2 tahapan:

1. Persiapan survei, yakni meliputi kajian kepustakaan, persiapan teknik, peralatan, dan mobilisasi tenaga.
2. Pelaksanaan survei yang dilakukan setelah kegiatan persiapan dan perencanaan survei dilakukan dengan matang

\section{3) Waktu Penelitian}

Waktu penelitian dilakukan selama 4 hari, yaitu pada hari senin, hari selasa, hari kamis dan hari sabtu. Waktu diambil selama 6 jam/hari, pada jam sibuk:

1. Ruas Jalan Arif Rahman Hakim (Lokasi I) dilakukan selama 2 hari, yaitu hari senin dan hari sabtu dibagi jam setiap 2 jam pagi (06.00-08.00), 2 jam siang (11.00-12.00), dan 2 jam sore (15.0017.00)

2. Ruas Jalan Manggis (Lokasi II) dilakukan selama 2 hari, yaitu hari selasa dan hari kamis dibagi jam setiap 2 jam pagi (06.00-08.00), 2 jam siang (11.00$12.00)$, dan 2 jam sore (15.00-17.00)

\section{Metode Analisis Data}

Metode yang digunakan dalam analisis data untuk penelitian ini adalah sebagai berikut:

1 Metode Pedoman Kapasitas Jalan Indonesia 2014 (PKJI'14)

2 Metode Analisis Regresi Linier Sederhana

\section{E. Tahapan Penelitian}

Tahapan penelitian merupakan cara efektif untuk mengetahui langkah-langkah yang dilakukan dalam suatu penelitian. Adapun langkah-langkah yang dilakukan adalah:

1. Persiapan dan studi pustaka

Persiapan yang dilakukan untuk mengenali lokasi penelitian.

2. Pengumpulan data

Pengumpulan data yaitu pencatat peristiwa keterangan atau dokumen. Data primer didapatkan secara langsung dilapangan.

3. Pengolahan data

Data yang akan digunakan untuk analisis data diperoleh melalui hasil survei arus lalu lintas. Pembacaan data dilakukan diluar waktu survei dengan bantuan formulir pencacahan arus lalu lintas dan Stop Watch. Analisis data yang akan digunakan yaitu data arus lalu lintas yang akan digunakan untuk analisis regresi linier sederhana diperoleh dari perhitungan oleh surveyor. Data berupa jumlah arus lalu lintas yang melewati ruas Jalan Arif Rahman Hakim (lokasi 1) dan ruas Jalan Manggis (lokasi 2).

4. Hasil dan pembahasan

Hasil dan pembahasan melakukan pengumpulan data volume arus lalu lintas dan data kondisi geometrik jalan sebagai data primer di ruas Jalan Arif Rahman Hakim dan ruas Jalan Manggis. Analisis data yang akan digunakan yaitu analisis regresi linier sederhana, koefisien korelasi (r), koefisien determinasi $\left(\mathrm{r}^{2}\right)$ serta uji signifikan dan hipotesis regresi linier diperoleh dari data arus lalu lintas perhitungan oleh surveyor. Setelah diperoleh 
nilai ekivalen kendaraan ringan (ekr) berdasarkan metode regresi linier sederhana, maka tahap selanjutnya menghitung kinerja ruas jalan sesuai Pedoman Kapasitas Jalan Indonesia tahun 2014 (PKJI'14). Data arus adalah data arus kendaraan/jam menurut jenisnya yang kemudian dikalikan nilai ekivalen kendaraan ringan (ekr) masing-masing untuk memperoleh satuan kendaraan ringan (skr).

5. Kesimpulan

Kesimpulan merupakan tahap akhir atau sebagai penutup dalam penelitian.

Kesimpulan juga merupakan ringkasan secara inti mengenai hasil penelitian.

\section{Hasil dan Pembahasan}

\section{Analisis Volume Lalu Lintas}

Volume lalu lintas yang dihitung adalah jumlah dari arus lalu lintas yang melewati lokasi penelitian selama waktu survey. Volume lalu lintas pada ruas Jalan Arif Rahman Hakim seperti pada Grafik berikut:

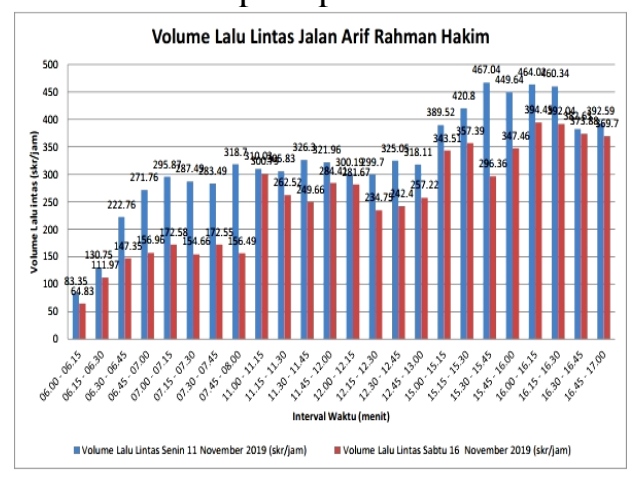

Gambar 3. Fluktuasi Volume Lalu lintas

\section{Analisis Regresi Linier \\ Menghitung Koefisien Regresi}

Data yang digunakan untuk mendapatkan nilai ekr adalah jumlah volume lalu lintas. Arus lalu lintas yang dihitung adalah jumlah dari arus lalu lintas yang melewati lokasi penelitian selama waktu survey. Berikut adalah data hasil penelitian di lokasi 1 pada ruas Jalan Arif Rahman Hakim Senin 11 November 2019.

Data volume lalu lintas kendaraan becak motor (variabel x) dan kendaraan ringan (variabel y) dari hasil survei di lapangan selanjutnya diolah sesuai dengan rumus Persamaan 2 dan 3, sehingga akan diperoleh persamaan normal untuk mencari koefisien regresi yang merupakan nilai ekivalen kendaraan ringan (ekr) yang dicari. Persamaan untuk mendapatkan persamaan normal seperti pada Tabel 3.
Tabel 3 Perhitungan Regresi Linier Senin 11 November 2019

\begin{tabular}{cccccc}
$\begin{array}{c}\text { Interval } \\
\text { Waktu }\end{array}$ & $\begin{array}{c}\text { BM } \\
\text { (X) }\end{array}$ & $\begin{array}{c}\text { KR } \\
(\mathrm{Y})\end{array}$ & $\mathrm{X}^{2}$ & $\mathrm{Y}^{2}$ & $\mathrm{XY}$ \\
& & & & & \\
& & & & & \\
\hline $06.00-06.15$ & 45 & 32 & 2025 & 1024 & 1440 \\
$06.15-06.30$ & 70 & 43 & 4900 & 1849 & 3010 \\
$06.30-06.45$ & 122 & 71 & 14884 & 5041 & 8662 \\
$06.45-07.00$ & 122 & 83 & 14884 & 6889 & 10126 \\
$07.00-07.15$ & 179 & 74 & 32041 & 5476 & 13246 \\
$07.15-07.30$ & 168 & 88 & 28224 & 7744 & 14784 \\
$07.30-07.45$ & 193 & 79 & 37249 & 6241 & 15247 \\
$07.45-08.00$ & 190 & 94 & 36100 & 8836 & 17860 \\
$11.00-11.15$ & 151 & 122 & 22801 & 14884 & 18422 \\
$11.15-11.30$ & 166 & 117 & 27556 & 13689 & 19422 \\
$11.30-11.45$ & 175 & 126 & 30625 & 15876 & 22050 \\
$11.45-12.00$ & 172 & 108 & 29584 & 11664 & 18576 \\
$12.00-12.15$ & 138 & 112 & 19044 & 12544 & 15456 \\
$12.15-12.30$ & 135 & 109 & 18225 & 11881 & 14715 \\
$12.30-12.45$ & 145 & 142 & 21025 & 20164 & 20590 \\
$12.45-13.00$ & 157 & 127 & 24649 & 16129 & 19939 \\
$15.00-15.15$ & 204 & 158 & 41616 & 24964 & 32232 \\
$15.15-15.30$ & 195 & 189 & 38025 & 35721 & 36855 \\
$15.30-15.45$ & 223 & 207 & 49729 & 42849 & 46161 \\
$15.45-16.00$ & 218 & 205 & 47524 & 42025 & 44690 \\
$16.00-16.15$ & 219 & 199 & 47961 & 39601 & 43581 \\
$16.15-16.30$ & 243 & 201 & 59049 & 40401 & 48843 \\
$16.30-16.45$ & 261 & 119 & 68121 & 14161 & 31059 \\
$16.45-17.00$ & 293 & 115 & 85849 & 13225 & 33695 \\
$\sum$ & 4184 & 2920 & 801690 & 412878 & 550661 \\
\hline Sumber Hasil Analisis 2020 & & &
\end{tabular}

Dari hasil perhitungan Tabel 3 diperoleh nilai:

$\begin{aligned} \sum \mathrm{x} & =4184 \\ \sum \mathrm{y} & =2920 \\ \sum \mathrm{x}^{2} & =801690 \\ \sum \mathrm{y}^{2} & =412878 \\ \sum \mathrm{xy} & =550661\end{aligned}$

Harga-harga dari hasil perhitungan Tabel 3 dimasukan ke rumus Persamaan 2 dan 3 sehingga terbentuk persamaan-persamaan berikut:

Perhitungan koefisien arah regresi $(b)$ dengan rumus Persamaan 2.

$$
\begin{aligned}
& b= \frac{n \sum x y-\sum x \cdot \sum y}{n \sum x^{2}-\left(\sum x\right)^{2}} \\
& b=\frac{(24)(550661)-(4184) \cdot(2920)}{(24) \cdot(801690)-(4184)^{2}} \\
& b=\frac{(13215864)-(12217280)}{(19240560)-(17505856)} \\
& b=\frac{(998584)}{(1724704)} \\
& b=0,58
\end{aligned}
$$

Perhitungan konstanta regresi (a) dengan rumus Persamaan 3.

$$
\begin{aligned}
& a=\frac{\sum y-b \sum x}{n} \\
& \alpha=\frac{(2920)-(0,59),(4184)}{(24)} \\
& \alpha=\frac{(2920)-(2426,72)}{(24)} \\
& \alpha=\frac{\left(49 a_{2} 28\right)}{(24)} \\
& \alpha=20,55
\end{aligned}
$$


Dengan memasukkan nilai hasil perhitungan Tabel 3 kedalam rumus Persamaan 2 dan 3, maka akan diperoleh nilainilai:

$$
b=0,58 \quad a=20,55
$$

Kemudian dimasukkan kedalam dalam rumus Persamaan 1 diperoleh model persamaan analisis regresi linier sederhana sebagai berikut:

$$
\begin{aligned}
& Y=a+b x \\
& Y=20,55+0,58 x
\end{aligned}
$$

Dari hasil analisis data volume arus lalu lintas interval waktu 15 menit maka diperoleh nilai ekivalen kendaraan ringan (ekr) untuk kendaraan becak motor (bentor) pada hari Senin 11 November 2019 sebesar: 0,58.

\section{Menghitung Koefisien Korelasi (r)}

Menghitung nilai koefisien korelasi dihitung dengan menggunakan rumus Persamaan 4.

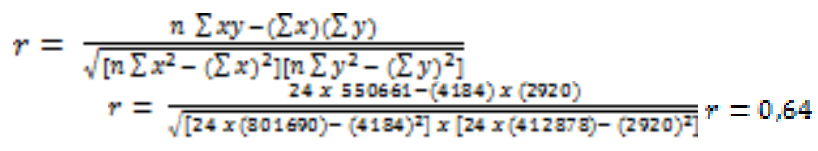

Dari rumus Persamaan 4 diperoleh koefisien korelasi (r) sebesar 0,64 dan hasil analisis berdasarkan Tabel 1 nilai koefisien korelasi (r) memberi arti bahwa terjadi hubungan yang kuat antara variabel independen (kendaraan becak motor) terhadap variabel dependen (kendaraan ringan).

\section{Menghitung Koefisien Determinasi $\left(\mathbf{r}^{2}\right)$}

Menghitung nilai koefisien determinasi $\left(\mathrm{r}^{2}\right)$ dihitung dengan menggunakan rumus Persamaan 5.

$$
\begin{aligned}
& K D=r^{2} \times 100 \% \\
& K D=0,64^{2} \times 100 \% \\
& K D=0,4096 \times 100 \% \\
& K D=0,4096(40,96 \%)
\end{aligned}
$$

Dari rumus Persamaan 5 diperoleh koefisien determinasi $\left(\mathrm{r}^{2}\right)$ sebesar $40,96 \%$ dan hasil analisis berdasarkan Tabel 2 koefisien determinasi $\left(\mathrm{r}^{2}\right)$ menunjukkan bahwa prosentase sumbangan pengaruh

\begin{tabular}{|l|l|l|l|l|}
\hline \multirow{2}{*}{ Lokasi } & Hari & $\begin{array}{l}\text { Nilai Ekr } \\
\text { Bentor }\end{array}$ & $\begin{array}{l}\text { Rata-rata Nilai Ekr } \\
\text { Bentor }\end{array}$ \\
\hline $\begin{array}{l}\text { Jalan Arif } \\
\text { Rahman Hakim }\end{array}$ & Senin & 0,58 & \multirow{2}{*}{0,55} \\
\cline { 2 - 3 } Jalan Manggis & Sabtu & 0,51 & & \\
\cline { 2 - 3 } & Selasa & 0,46 & \multirow{2}{*}{0,46} \\
\end{tabular}

variabel independen (kendaraan becak motor) terhadap variabel dependen (kendaraan ringan) adalah sebesar 40,96\% sedangkan sisanya sebesar 59,04\% dipengaruhi oleh variabel lain yang tidak dimasukkan atau tidak dibahas dalam penelitian ini. Nilai koefisien determinasi $\left(\mathrm{r}^{2}\right)$ yang dihasilkan membuktikan bahwa pengaruh antara variabel bebas yakni kendaraan becak motor (bentor) dengan variabel terikat kendaraan ringan adalah tinggi $\left(36 \%<\mathrm{r}^{2}<64 \%\right)$

\section{A. Hasil Nilai Ekivalen Kendaraan Ringan (ekr)}

Hasil perhitungan nilai ekr untuk kendaraan bentor pada kedua tempat lokasi penelitian menggunakan metode analisis regresi linier sederhana seperti pada Tabel 4 .

Tabel 4 Rekapitulasi Nilai Ekr Berdasarkan Analisis Regresi Linier

\section{Analisis Kinerja Lalu Lintas Jalan dengan Metode PKJI 2014}

Rekapitulasi hasil perhitungan kinerja ruas jalan menggunakan PKJI 2014 dan analisis regresi linier seperti pada Tabel 5 dan Tabel 6 .

Tabel 5 Analisis Kinerja Lalu Lintas Jalan Pada Ruas Jalan Arif Rahman Hakim

\begin{tabular}{ccccc}
\hline Jam Puncak & $\begin{array}{c}\text { Q } \\
\text { skr/jam }\end{array}$ & $\begin{array}{c}\mathrm{V}_{\mathrm{B}} \\
\mathrm{km} / \mathrm{jam}\end{array}$ & $\begin{array}{c}\mathrm{D}_{\mathrm{J}} \\
\mathrm{Q} / \mathrm{C}\end{array}$ \\
\hline \multicolumn{5}{c}{ Hari Senin } \\
\hline $07.00-08.00$ & 1186 & 2371,62 & 38,22 & 0,50 \\
$11.00-12.00$ & 1264,1 & 2371,62 & 38,22 & 0,53 \\
$15.30-16.30$ & 1841 & 2371,62 & 38,22 & 0,78 \\
\hline \multicolumn{6}{c}{ Hari Sabtu } \\
\hline $07.00-08.00$ & 656,28 & 2371,62 & 38,22 & 0,28 \\
$11.00-12.00$ & 1097,38 & 2371,62 & 38,22 & 0,46 \\
$16.00-17.00$ & 1530,07 & 2371,62 & 38,22 & 0,65 \\
\hline \multicolumn{6}{c}{ Sumber Hasil Analisis 2020 }
\end{tabular}

Tabel 6 Analisis Kinerja Lalu Lintas Jalan Pada Ruas Jalan Manggis

\begin{tabular}{ccccc}
\hline Jam Puncak & $\mathrm{Q}$ skr/jam & $\begin{array}{c}\mathrm{V}_{\mathrm{B}} \\
\mathrm{km} / \mathrm{jam}\end{array}$ & $\begin{array}{c}\mathrm{D}_{\mathrm{J}} \\
\mathrm{Q} / \mathrm{C}\end{array}$ \\
\hline \multicolumn{5}{c}{ Hari Selasa } \\
\hline $07.00-08.00$ & 265,78 & 2371,62 & 38,22 & 0,11 \\
$12.00-13.00$ & 245,4 & 2371,62 & 38,22 & 0,10 \\
$16.00-17.00$ & 298,76 & 2371,62 & 38,22 & 0,13 \\
\hline \multicolumn{5}{c}{ Hari Kamis } \\
\hline $07.00-08.00$ & 250,95 & 2371,62 & 38,22 & 0,11 \\
$11.30-12.30$ & 236,97 & 2371,62 & 38,22 & 0,10 \\
$16.00-17.00$ & 276,71 & 2371,62 & 38,22 & 0,12 \\
\hline \multicolumn{5}{c}{ Sumber Hasil Analisis 2020 }
\end{tabular}

\section{Kesimpulan}

\section{A. Kesimpulan}

Berdasarkan perhitungan yang telah dilakukan pada penelitian ini, maka dapat diambil beberapa kesimpulan sebagai berikut:

1. Hasil perhitungan nilai ekivalen kendaraan ringan (ekr) untuk kendaraan becak motor (bentor) pada ruas Jalan Arif Rahman Hakim diperoleh nilai ekr untuk kendaraan bentor sebesar 0,55 dan ruas Jalan Manggis diperoleh nilai ekr untuk kendaraan bentor sebesar 0,46 .

2. Hasil analisis kinerja ruas Jalan Arif Rahman Hakim dan ruas Jalan Manggis diperoleh nilai derajat kejenuhan $\left(D_{J}\right)<0,85$. Hasil nilai derajat kejenuhan $\left(\mathrm{D}_{\mathrm{J}}\right)$ menunjukkan bahwa ruas Jalan Arif Rahman Hakim dan ruas Jalan Manggis sangat layak untuk melayani arus lalu lintas di jam sibuk.

\section{B. Saran}

Berdasarkan analisis data dan survei lapangan, maka saran-saran yang bisa disampaikan adalah sebagai berikut:

1. Untuk mendapatkan hasil yang optimal dalam menghitung volume lalu lintas, sabaiknya satu orang surveyor hanya menghitung jumlah dari satu jenis kendaraan saja. 
2. Penelitian ini dilakukan dengan cara manual maka tingkat ketelitian tidak begitu tinggi. Untuk mempertinggi tingkat ketelitian, dalam artian memperkecil kecil kesalahan maka sebaiknya digunakan peralatan seperti kamera dan video otomatis yang diletakkan di ruas jalan tempat melakukan pengambilan data volume lalu lintas.

3. Dari hasil penelitian yang telah dilakukan, perlu dilakukan penelitian lanjutan yang sama pada ruas jalan lainnya di Kota Gorontalo dengan kondisi arus lalu lintas yang mirip dengan ruas Jalan Arif Rahman Hakim dan Jalan Manggis agar supaya ada pembanding guna mendapatkan nilai ekivalen kendaraan ringan (ekr) yang tepat untuk ruas jalan di Kota Gorontalo.

\section{Daftar Pustaka}

[1] Juniarta, I. W., Widana Negara, I. N. dan Jaya Wikrama, N. A., 2012. Penentuan Nilai Ekivalensi Mobil Penumpang Pada Ruas Jalan Perkotaan. Jurnal Ilmiah Elektronik Infrastruktur Teknik Sipil .

[2] Kementerian Pekerjaan Umum, 2014. Pedoman Kapasitas Jalan Indonesia (PKJI) Kapasitas Jalan Perkotaan. Jakarta
[3] Khisty C.J dan Lall B.K. 2005. Dasar Dasar Rekayasa Transportasi. Jakarta: Erlangga.

[4] Lendeng, L. E., Lalamentik, L. G. dan Pandey, S. V., 2018. Analisa Nilai Ekuivalensi Mobil Penumpang (emp) Dengan Metode Time Headway Dan Regresi Linear Berganda. Jurnal Sipil Statik , 735-742.

[5] Palilingan, A. G., Pandey, S. V. dan Rumayar, A. L., 2018. Studi Penetapan Nilai EMP Dengan Metode Rasio Headway Dan Analisa Regresi Linier. Jurnal Sipil Statik, 315-322.

[6] Peraturan Pemerintah Indonesia, 2009, Undang-undang Nomor 22 Tahun 2009 Tentang Lalu Lintas dan Angkutan Jalan, Departemen Perhubungan, Jakarta.

[7] Peraturan Pemerintah Republik Indonesia, 2006, PP No. 34 Tahun 2006 Tentang Jalan, Jakarta.

[8] Sugiyono, 2013. Metodelogi Penelitian Kuantitatif Kualitatif dan R\&D Bandung: Alfabeta

[9] Taidi, F., Rompis, S. Y. dan Manoppo, M. E., 2018. Analisis Nilai Ekivalensi Mobil Penumpang Pada Simpang Bersinyal Di Kota Manado. Jurnal Sipil Statik , 91-100.

[10] Tamin, O. Z. 2000. Perencanaan Dan Pemodelan Transportasi. Bandung: ITB.

[11] Utami, P. K. 2009. Penentuan Nilai Ekuivalensi Mobil Penumpang Pada Bundaran. Surakarta.

[12] Wulandari, A. 2011. Studi Penetapan Nilai Ekuivalensi Mobil Penumpang Pada Kendaraan Berat Menggunakan Metode Time Headway Dan Analisis Regresi Linier. Surakarta. 